\title{
Negotiation Inaction Inertia: A Dynamic Model of the Impact of Missed Opportunities on Negotiation Decisions in Multi-issue Disputes
}

\author{
Lesley G. Terris, ${ }^{1, \mathbf{a}}$ Noya Lishner-Levy ${ }^{2, \mathrm{~b}}$ and Orit E. Tykocinski ${ }^{3, \mathrm{~b}}$ \\ aLauder School of Government, Diplomacy and Strategy, \\ Interdisciplinary Center (IDC) Herzliya, Po Box 167, 8 Ha'universita Street, \\ Herzliya, 4610101, Israel \\ bBaruch Ivcher School of Psychology, Interdisciplinary Center (IDC) \\ Herzliya, Po Box 167, 8 Ha'universita Street, Herzliya, 4610101, Israel \\ lterris@idc.ac.il;noya.lishnerlevy@post.idc.ac.il; oritt@idc.ac.il
}

Received 1 November 2019; accepted 1 March 2020

\begin{abstract}
Negotiations aimed at resolving international disputes often end in deadlock. In the current article, we focus on deadlocks triggered by missed opportunities. The consequences of missing an advantageous opportunity have been studied extensively in the field of psychology within the context of the inaction inertia effect. The concept was recently introduced into the negotiation literature. Forgoing an attractive action opportunity creates vulnerability to regret and increases the likelihood of forgoing

1 Lesley G. Terris is a Senior lecturer at the Lauder School of Government, Diplomacy and Strategy, Interdisciplinary Center (IDC) Herzliya, Israel. Employing diverse research methodologies, her research focuses on conflict processes, and negotiations and mediation in interstate and intrastate conflicts with a focus on the role of leadership, negotiation inaction inertia, and negotiation credibility.

2 Noya Lishner Levy is a Ph.D. candidate at the Department of Education at the Hebrew University in Jerusalem, and a graduate of the MA program of the School of Psychology at the Interdisciplinary Center (IDC) Herzliya, Israel. Her research area is the psychology of judgment and decision making with a focus on psychological processes in negotiation.

3 Orit E. Tykocinski is a faculty member in the School of Psychology at the Interdisciplinary Center (IDC) Herzliya, Israel. Her research explores the role of regret in intuitive judgments and the phenomenon of inaction inertia in consumer behavior and political negotiations, among others.
\end{abstract}


subsequent inferior opportunities, even if they still have positive value. The current article deepens the applicability of inaction inertia to international negotiations, by adopting a new multi-step multi-issue paradigm, which better approximates real-life negotiations. Using the new platform, we demonstrate the inaction inertia effect in a dynamic negotiation setting and link an individual's inertia mindset to the experience of regret. The methodology and analysis presented will help researchers and practitioners explain inertia-induced deadlocks, and facilitate interventions that expedite successful resolutions.

\section{Keywords}

inaction inertia - negotiations - negotiation deadlocks - psychological barriers conflict resolution - regret

The social sciences field is characterized by ever-increasing accessibility to information and growing communication and collaboration between scholars in different fields of study. ${ }^{4}$ This process has tremendously enriched our understanding of social phenomena and expanded available toolboxes for effective policy-making and interventions. The negotiation literature has benefited considerably from this process in recent years, in particular, from research conducted in the field of social psychology. Studies providing a view into psychological, cognitive, and affective processes to which decisionmakers involved in negotiations are subject, have contributed greatly to our understanding of factors and processes and that may set constraints on the ability to reach negotiated agreements that end conflicts. Some psychological biases that have been found to account for actors' negotiating failures include framing - negotiators are more inclined to make concessions when a negotiation offer is framed in the domain of losses (by stressing the cost of offer rejection) than when it is framed in the domain of gains (by stressing the benefit of offer acceptance) (Bazerman, Magliozzi \& Neale 1985; De Dreu \& McCusker 1997); reactive devaluation - concessions made by the opponent tend to be perceived as less significant than identical concessions made by oneself (Ross \& Stillinger 1991); anchoring effects - negotiators tend to orient offers around anchors even when the anchors are not necessarily relevant (Epley \& Gilovich 20o6; Galinsky \& Mussweiler 2001; Kahneman 1992; Whyte \& Sebenius 1997);

4 The authors gratefully acknowledge financial support from the Israel Science Foundation under Grant 1870/16. All authors contributed to the study equally. 
and optimistic overconfidence - negotiators tend to overestimate their own capabilities and underestimate those of the other side, resulting in overestimation of their leverage in negotiations (Bazerman et al. 2000; McDermott 2009; Kahneman \& Tversky 200o; Van Evera 2001). Emotions, too, have been found under certain conditions to limit the ability of negotiators to accurately assess bargaining situations (Loewenstein \& Lerner 2003; Renshon \& Lerner 2012; Renshon, Lee \& Tingley 2017).

The current article focuses on yet another psychological effect, inaction inertia, which has been well established in the field of psychology to explain the consequences of missed opportunities, mostly in consumer behavior. ${ }^{5}$ In 2016, an initial demonstration of the potential of inaction inertia for international negotiations was established by Terris and Tykocinski (2016). Although that research clearly confirmed the potential of the concept for understanding deadlocks in international negotiations, it also highlighted the limitation of the classic scenario-based methodology in capturing the complex and dynamic nature of real-life negotiations. In the current article, we improve the applicability of the concept of inaction inertia to the unique characterizations of international negotiations. To this end, we developed a dynamic methodology for the exploration of negotiation inaction inertia, which more accurately simulates multi-issue dynamic negotiation settings, and which is more likely to be useful for researchers and practitioners in the field.

A successful adaptation of the concept of inaction inertia to the field of negotiations is very important, in particular because it has the potential to explain negotiation deadlocks. Traditional negotiation research offers numerous explanations for deadlocks that largely derive from rationalist approaches. Fearon (1995) suggests four main strategic barriers to successful political negotiations: 1) poor information or incentives to misrepresent information; 2) commitment problems; 3) issue indivisibility; and 4) audience costs. Mutual mistrust has also been tied to missed opportunities and negotiation failures (Golan 2015; Kydd 2005; Larson 1997). In this article, we seek to enrich this extant literature with an inaction inertia-based explanation of negotiation deadlocks. Unlike other causes of deadlocks, inertia-induced deadlocks are probably more amenable to change with interventions. Therefore, understanding the process of inaction inertia is very important.

We begin with a discussion of inaction inertia research in both psychology and international negotiations. We discuss the limitation of the classic scenario approach and introduce the online negotiation task that was developed

5 For a review of inaction inertia research in the field of psychology, see Van Putten et. al. (2014). 
for this study to simulate the dynamic and interactive nature of negotiations across multiple issues. We then analyze the results of an experiment conducted using the online platform with particular focus on the role of regret in prompting inaction inertia-induced negotiation decisions. Our results support and expand upon previous inaction inertia findings in the international context, showing inaction inertia in a dynamic setting and strengthening its link to the avoidance of regret.

\section{Inaction Inertia}

Researched extensively in the field of psychology, the phenomenon of inaction inertia describes a behavior pattern whereby missing out on an initial attractive action opportunity reduces the likelihood that subsequent inferior opportunities will be taken in the same action domain, even if these opportunities still have positive value. The realization that a golden opportunity was forgone creates susceptibility to regret. By quickly dismissing subsequent inferior opportunities, regret can be avoided, at least in the short term. For example, in Tykocinski, Pittman, and Tuttle (1995), participants were asked how likely they would be to join a frequent flyer program before a trip they were planning. The participants were asked to imagine that they had considered joining once before, prior to a previous trip, but had failed to join. The results of the experiment showed that the relative attractiveness of the forgone opportunity compared to the current offer had a significant effect on participants' willingness to join the program. Participants who had missed out on an opportunity to gain a large number of miles by failing to join earlier (large difference condition, LD) were least likely to join the program now, compared to participants for whom the difference between the forgone opportunity and the current one was small (small difference condition, SD), and compared to participants who had no history of a missed opportunity (control group). Subsequent studies showed that participants were spontaneously framing this forgone opportunity as a loss and that the primary underlying motivation for inaction inertia was avoidance of anticipated regret if the current opportunity was taken. In addition, experiments showed that the effect occurs even when the principal actor is not directly responsible for missing the initial opportunity (Butler \& Highhouse 2000, 2001; Sevdalis, Harvey \& Yip 2006; Pittman et al. 2008).

In the field of psychology, inaction inertia was explored mostly within the context of consumer decisions and has been employed to explain human behavior in varied domains such as commodity purchases, the effect of promotions, marketing, and investment decisions (Liu Hsin-Hsien \& Chou Hsuan-Yi 
2018, 2019; Tsiros \& Hardesty 2010; Zeelenberg \& Van Putten 2005). Inaction inertia was also explored to account for the influence of bonuses on academic procrastination (Pittman et al. 2008).

The key to the inaction inertia mindset is the juxtaposition of a forgone superior opportunity with an inferior, but good, opportunity, which is still available. This juxtaposition triggers an unpleasant counterfactual thinking process ("if only I had acted sooner ...") and provides the potential for a sense of loss and the experience of regret. Thus, this mindset is particularly relevant to international negotiations, where offers are put on the table sequentially and at each phase negotiators can compare and contrast what is available now to previous forgone offers.

Although it is difficult to ascertain beyond doubt that deadlocks in actual international negotiations result from an inaction inertia dynamic, some negotiations are highly suggestive of this pattern. It seems that a forgone golden opportunity, instead of encouraging cutting one's losses and achieving a quick resolution, often creates a psychological mindset which prompts further inaction and makes settlement less likely. Yet, how can we tell that indeed settlements are not rejected simply because they failed to meet the needs of the state? One clue for this is given in retrospect - when we see that after rejecting a settlement proposal, the party later resolves on settlement terms that are no better, and sometimes even inferior, to terms previously rejected. On this point, Maoz (2006: 386) determines that if a party at time $t+1$ agrees to an offer it rejected at time $t$, thus derailing a possible settlement, "then the policy at time $t$ had most likely been a failure." The course of events prompted by Egyptian President Anwar Sadat's interim agreement proposal to Israel in 1971 in the aftermath of the War of Attrition is illustrative of such an inaction inertia pattern. On February 4, Sadat presented a proposal for the disengagement of military forces along the Suez Canal. The proposal addressed three main points of contention: the degree of Israeli withdrawal, an Egyptian presence east of the canal, and linkage to an overall settlement. Although the Egyptian initiative provided Israel with a way out of the conflict with its strongest rival, Israel practically ignored the Egyptian offer with Israeli Prime Minister Golda Meir sharply criticizing Sadat's lack of flexibility in her speech to the Israeli Knesset on February 9 (Maoz 2006: 413; Quandt 2005: 88). This missed opportunity for Israel set the stage for an inaction inertia mindset. Shortly afterwards, Israel rejected an additional offer, this time by the US, that basically reiterated the terms of Sadat's interim agreement proposal but added the explicit stipulation that after this step, Egypt and Israel would work towards an overall settlement based on UN Resolution 242 (Kissinger 1979, 1982). Thus, another opportunity for an agreement was forgone. 
Profoundly frustrated with the Israeli reaction to his 1971 initiative and to subsequent American efforts, on October 6, 1973, Egypt in coordination with Syria launched a surprise military attack on Israel. Ending three weeks later, the war cost Israel the lives of close to 3000 soldiers and \$10 billion (Maoz 2006: 415-417). Moreover, the sides had come no closer to a territorial agreement than they were prior to the fighting.

Efforts to bring the sides to an interim settlement resumed after the October War. Mediated by US Secretary of State Henry Kissinger, this time the talks resulted less than a year later in January 1974, in the signing of the Sinai I Agreement. Notably, by accepting the Sinai I deal, Israel agreed to make greater concessions in return for a military disengagement with Egypt than those it had refused to make in 1971 (Terris 2017: $107 \mathrm{fn} 79$ ). ${ }^{6}$ The fact that Israel ended up agreeing to terms it had previously rejected suggests that indeed Sadat's offer in 1971 was a golden opportunity which was missed, resulting in an inertia mindset and a war that could have been prevented. This realization echoes in the bitter words of officials who were involved in Israel's decision-making during that period. In fact, Moshe Dayan who served as Israel's Minister of Defense at the time and supported, although reluctantly, Golda Meir's view on Sadat's proposal would later explicitly blame Meir for missing the opportunity that could have prevented the October War. Similar sentiments were expressed over the years by additional decision makers such as Abba Eban (1992: 504-6) and Gad Yaacobi (Maoz 2006: 416-417).

Terris and Tykocinski also identified an inaction inertia pattern in the more recent negotiations between Israel and Hamas (2006-2011) for the release of the captured Israeli soldier Gilad Shalit. Here too, Israel, after five long years of negotiations, ended up accepting a deal that was no better than the one offered by Hamas just two months after the soldier was captured. For a detailed discussion of the inaction inertia patterns in these events, see Terris and Tykocinski (2016).

Finally, the potential of the inaction inertia concept for understanding international relations has been tested in experimental research reflecting two types of negotiation settings. However, the experiments conducted in the study, which largely relied on the classic scenario methodology used in psychology (one-opportunity/one-issue decisions) did not fully capture the complex qualities and dynamic nature of international negotiations. In the first experiment, the participants were asked to assume the role of a negotiator trying to bring about the release of an Israeli soldier who had been captured by the fictitious "Islamic Liberation Army." The negotiator had to decide whether

6 For further details on the proposal and final agreement terms, see Terris 2017: 107, 114-15. 
to accept the terrorists' demands for the release of the soldier. In the second experiment, the scenario involved territorial negotiations between two fictitious countries. The inaction inertia effect was obtained in both experiments. For example, in the hostage negotiations, the current demands presented to the participants entailed Israel's release of 700 Palestinian prisoners in exchange for the return of the captured Israeli soldier. In the Large Difference condition (LD), participants were told that this offer had been preceded by a much superior offer entailing the release of 400 Palestinian prisoners, which had been rejected by the Israeli government. Participants in this LD condition were significantly less likely to accept the current deal compared to participants in the Small Difference condition (SD), who were told of a previous forgone offer demanding the release of 66o Palestinian prisoners, as well as participants in the control group where no previous offer was mentioned.

The results of the hostage negotiation experiment also showed that female participants were less likely to enter into an inaction inertia behavior pattern than male participants. Because gender differences were not found in previous inaction inertia studies, it was suggested that the observed differences could be linked to the public nature of international relations, and that men are more status conscious than women. Therefore, men may be more motivated to avoid action that could leave them susceptible to public criticism (Tannen 1994). Gender differences are also consistent with the Women and Peace hypothesis (Tessler, Nachtwey \& Grant 1999), which claims that women have a higher tendency to compromise and a lower tendency for violence relative to men.

The fact that the inaction inertia phenomenon was reproduced by using scenario methodology, as well as detected in the case analysis, underlines the relevance of the concept of inaction inertia to international negotiation contexts. It became clear though that to more fully integrate the concept into the international negotiation literature, it is necessary to better capture the traits of international negotiations in experimental research. Thus, a more dynamic methodology is called for, one that can authentically reflect the inherent complexity of multi-step negotiations involving multiple issues.

To explore inaction inertia in a setting that more accurately simulates international negotiations, we developed an online negotiation platform that allows participants to engage in negotiations vis-à-vis an opponent (computer agent) over multiple issues and over multiple rounds of negotiations. The development of the negotiation platform was inspired by Dehghani, Carnevale \& Gratch (2014), who used computer-based negotiation methodology to explore the impact of emotions on negotiations.

The negotiation task designed for the inaction inertia experiment entailed talks between two fictitious African states, Kibagho and Naphura, over four 
assets of varying weights, ranked from most to least important: territory, prisoners, water sources, and religious artifacts. Each of the assets was divided into units, allowing the participants and the computer agent to formulate package deals of varying scopes and value. The assets and number of units available for each asset are depicted in Fig. 1 below. The assets are listed in order of descending importance (weight) for the people of Naphura.

\section{Method}

\section{Participants}

216 users ( 139 male, 77 female; mean age $=36.3$ years, SD=9.4) of the Prolific academic platform (see www.prolific.co) originating from English-speaking countries (USA, Canada and England) participated individually in this experiment and paid $£_{5}$. ०० each. The participants were randomly assigned to either a large-difference condition ( $\mathrm{LD}=46$ participants), a small-difference condition ( $\mathrm{SD}=48$ participants), or a control group ( 46 participants). Participants who accepted the initial offer $(n=72)$ were not included in the analysis because by accepting the first offer they practically avoided negotiation altogether and had no experience of a missed opportunity. In addition, it is likely that such quick termination of the negotiation indicated that these participants were merely seeking to obtain payment in return for the smallest amount of time and effort. For these theoretical and practical reasons, these participants were not included in further analysis.

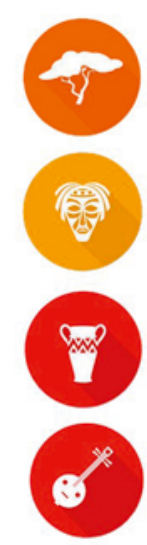

FIGURE 1

Territory: 10 units. Each unit represents $10 \%$ the disputed territory.

Prisoners: 6 units. Each unit represents 50 prisoners: 200 Kibaghian and 100 Naphurian prisoners.

Water: 6 units. Each unit represents access to one water source.

Religious Artifacts: 6 units. Each unit represents an artifact that is considered sacred by both states

Disputed assets 
The participants were tasked to represent the state of Naphura in the negotiations with Kibagho (the computer agent) over the distribution of the disputed assets. Similar to moving pawns on a board, by clicking on the disputed assets on the computer screen, the participants moved the asset units to create offers, placing them either on their own side or the opponent's side of the board. The game opened with a presentation of the first offer by Kibagho. In each negotiation round, participants (who were all representing Naphura) evaluated a settlement offer made by Kibagho (computer agent) and then had to decide whether to accept the offer, reject and submit a Naphurian counter-offer, or terminate the negotiations (see Fig. 2 below).

The total value of each offer was calculated based on the numeric weight of the asset times the number of units offered, summed across the assets, and was presented to the participants on the right side of the screen, next to the negotiation board. These offer values helped participants consider the attractiveness of offers they made, and helped them assess the attractiveness of the offers made by the opponent. In addition, as the values of previous offers were kept on the screen, participants were able to judge the value of any current offer in context. The computer agent was programmed to accept a participant's proposal if it had a value that was lower than, or equal to, the value of Kibagho's offer in the next round. If no agreement was reached after ten rounds, Kibagho terminated the negotiations.

After three rounds, participants received a "news bulletin" of current events (see Fig. 3). To set the stage for inaction inertia in the large-difference experimental condition, a very attractive first settlement offer by Kibagho was to be

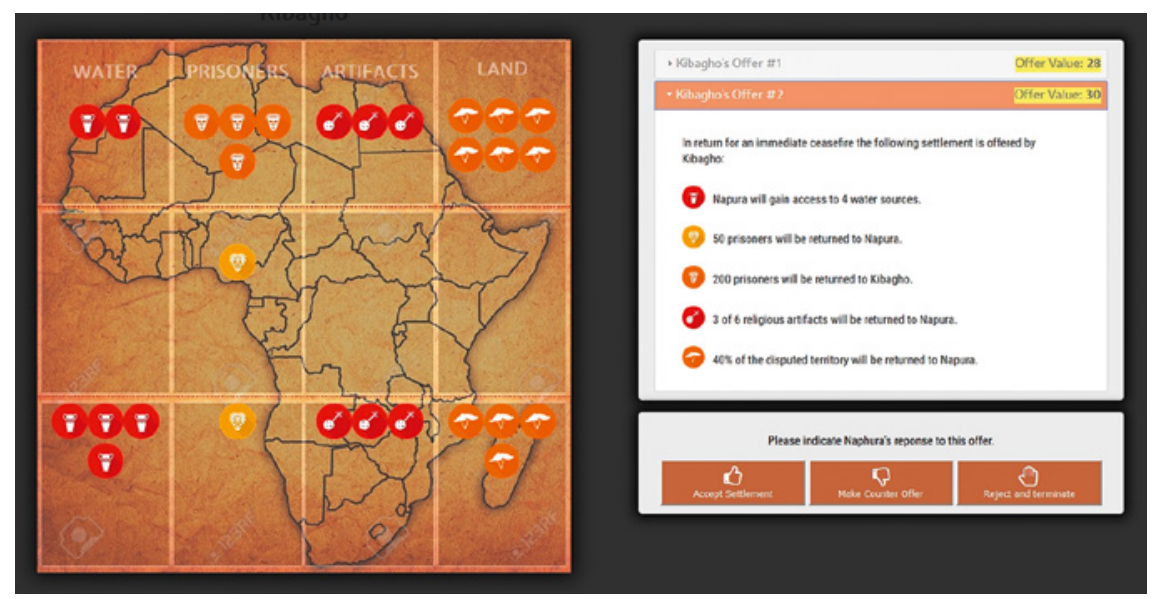

FIGURE 2 Screenshot of the negotiation board 


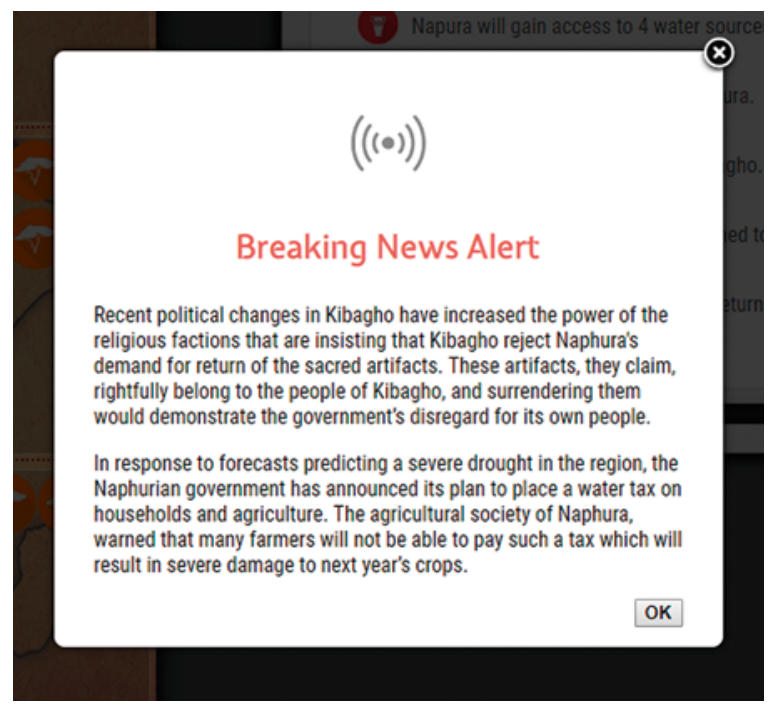

FIGURE 3 Sample news bulletin

followed by dramatically inferior offers. Therefore, the news bulletins were included so that the changes in the value of Kibagho's offers would not seem arbitrary, but rather the result of relevant political and economic events. In addition, the bulletins were intended to contribute to the realistic feel of the setting and enhance participants' involvement.

Each participant was randomly assigned into one of three conditions: large difference (LD), small difference (SD) or the control group. The conditions differed in Kibagho's first offer. In the LD condition Kibagho's first offer was 22 value points higher (better) than that made by Kibagho in round two. In the SD condition, Kibagho's first offer was again superior to the second, but the difference between the offers was only 15 value points. The second offer made by Kibagho was identical for all conditions. However, in the control condition this offer was the first offer presented to the participants (see Table 1).

\section{Introduction Video}

A short white-board introductory video describing the Kibagho-Naphura conflict was shown to the participants before they commenced the negotiation task. The video explained the historical background of the conflict and the significance of the disputed assets. The role of the participant as a Naphurian senior government official tasked to head the negotiations was explained and the disputed assets were introduced and then ranked according 
TABLE 1 Kibagho's (computer agent) settlement offers to Naphura

\begin{tabular}{|c|c|c|c|c|c|}
\hline Offers & $\begin{array}{l}\text { Territory } \\
\text { 1o units; } \\
\text { weight=4 }\end{array}$ & $\begin{array}{l}\text { Prisoners } \\
2 \text { units; } \\
\text { weight }=3\end{array}$ & $\begin{array}{l}\text { Water } \\
6 \text { units; } \\
\text { weight }=2\end{array}$ & $\begin{array}{l}\text { Artifacts } \\
6 \text { units; } \\
\text { weight=1 }\end{array}$ & $\begin{array}{l}\text { Total Value } \\
\text { for Naphura }\end{array}$ \\
\hline
\end{tabular}

Large

Difference 8

2

4

5

$5^{\circ}$

(LD)

Offer \# 1

Small

Difference

6

2

4

5

43

(SD)

Offer \# 1

Offer \# 2 * 4

$\begin{array}{llll}1 & 3 & 3 & 28 \\ 1 & 4 & 3 & 30 \\ 2 & 2 & 4 & 30 \\ 2 & 3 & 3 & 31 \\ 2 & 3 & 2 & 34 \\ 2 & 3 & 3 & 35 \\ 2 & 4 & 3 & 37 \\ 2 & 4 & 3 & 41 \\ 2 & 4 & 3 & 41\end{array}$

to their importance for the Naphurian people, from most important to least important (territory, return of prisoners, control over water sources, return of religious artifacts). The instructional video is available online at: https:// tinyurl.com/negotiations18.

\section{Procedure}

The experiment was conducted in three phases. The first phase introduced participants to the dispute; participants watched the introductory video and received a detailed explanation of how to use the online negotiation board.

In the second phase, participants were randomly assigned to one of the three conditions and were asked to begin the computerized negotiation task as chief negotiator of Naphura. Participants were led to believe that they were playing against another person, who was performing a similar role on behalf of Kibagho, rather than against a computer agent. It is likely that the use of a known experimental platform (Prolific Academic) contributed to creating this 
desired impression; indeed, in post-experiment interviews, participants indicated that they did feel the other party was an actual person.

The third phase took place after the negotiations ended. Participants were asked to indicate their gender and age and to share any comments and thoughts concerning their experience in the negotiations in a free form text box.

\section{Results and Discussion}

\section{Negotiation Rounds by Condition}

As expected, the pattern of average number of rounds played by participants in the different conditions was consistent with the inaction inertia effect (see Table 2). A Poisson regression analysis revealed that the likelihood that the control group would play more rounds than the LD group was low $(B=-.21$, $\mathrm{SE}=.07$, $\mathrm{Sig}=.004$, Odds Ratio $=.81$ ). Similarly, the likelihood that the SD group would play more rounds than the LD group was also low $(\mathrm{B}=-.17, \mathrm{SE}=.07$, Sig = .o19, Odds Ratio $=.84$ ).

Consistent with our prediction, participants who initially missed a far more attractive offer were more likely to continue rejecting offers by Kibagho.

\section{Sense of Regret}

Previous research on inaction inertia has attributed the effect to an individual's desire to avoid regret (Butler \& Highhouse 2000). However, because in the current experiment the negotiations were eventually terminated; it was possible that in retrospect the participants would be able to recognize a sense of regret and report it. Therefore, we analyzed the content of participants' free form feedback to identify relevant emotions. One participant wrote for example, "I wish I'd taken their first offer! That was the best one. I'm also frustrated with myself as I should have started with a much higher offer than I did, so I ended up leaving myself little room to negotiate with. In the last few counter

TABLE 2 Average negotiation rounds (M) by condition

\begin{tabular}{llll}
\hline & N & M & SD \\
\hline Large difference & 73 & 5.78 & 2.84 \\
Small difference & 72 & 4.85 & 2.4 \\
Control & 71 & 4.58 & 2.16 \\
\hline
\end{tabular}


offers, I basically kept putting in the same thing, hoping they would offer a little more ...!"

The text comments that were collected in the post-negotiation questionnaire were encoded into nine categories of feelings and emotions, presented in Table 3. The content classification was conducted by two coders blind to the conditions; inter-coder reliability was very high (agreement $=98 \%$; Cohen's Kappa $=.96$ ). Inconsistencies were resolved by discussion with the authors.

A chi-square test of independence was performed to examine the frequencies of these emotions in each condition. Regret was the only emotion which was found to be significantly different across the conditions $\left(\chi^{2}(2, N=117)=\right.$ 13.61, $\mathrm{p}<.001)$. Participants in the control and the SD conditions were less likely to experience regret compared to participants in the LD condition. These results are consistent with the inaction inertia mind-set and with the classic characterization of the inaction inertia process. They are, therefore, a further signifier of a successful transition from the static scenario-based demonstrations of the effect, into the dynamic, multi-step, multi-issue model used in the current study.

TABLE 3 Chi-square analysis of feelings and emotions by condition

\begin{tabular}{|c|c|c|c|c|c|c|c|}
\hline & \multicolumn{2}{|c|}{$\begin{array}{l}\text { Large } \\
\text { Difference } \\
\mathrm{N}=36\end{array}$} & \multicolumn{2}{|c|}{$\begin{array}{l}\text { Small } \\
\text { Difference } \\
\mathrm{N}=40\end{array}$} & \multicolumn{3}{|c|}{$\begin{array}{l}\text { Control } \\
\mathrm{N}=41\end{array}$} \\
\hline & $\mathbf{N}$ & $\%$ & $\mathbf{N}$ & $\%$ & $\mathbf{N}$ & $\%$ & Chi-Square \\
\hline Regret & 14 & 38.9 & 8 & 20 & 2 & $4 \cdot 9$ & $13.61^{*}$ \\
\hline $\begin{array}{l}\text { Frustration in } \\
\text { general }\end{array}$ & 7 & 19.4 & 5 & 12.5 & 5 & 12.2 & 1.01 \\
\hline Frustration at self & 1 & 2.8 & 2 & 5 & o & o & 2.04 \\
\hline Upset at myself & 6 & 16.7 & 4 & 10 & o & o & 6.98 \\
\hline $\begin{array}{l}\text { Frustrated by } \\
\text { opponent }\end{array}$ & 9 & 25.0 & 8 & 20 & 3 & $7 \cdot 3$ & 4.59 \\
\hline Angry at self & 1 & 2.8 & o & o & o & o & 2.27 \\
\hline $\begin{array}{l}\text { Angry at the } \\
\text { opponent }\end{array}$ & 1 & 2.8 & 3 & $7 \cdot 5$ & 1 & 2.4 & 1.55 \\
\hline Positive in general & 20 & 55.6 & 23 & $57 \cdot 5$ & 31 & 75.6 & 4.18 \\
\hline
\end{tabular}

${ }^{*} \mathrm{p}<.001$ 
In conflict situations, parties often miss an opportunity to reach a settlement that would end their dispute. Rarely, however, do political decisionmakers admit, express regret or take responsibility for missed opportunities. As former US Secretary of Defense Robert McNamara aptly expressed in an interview in The New York Times: "People don't want to admit they made mistakes. This is true of the Catholic Church, it's true of companies, it's true of nongovernmental organizations and it's certainly true of political bodies" (Power 2003). Indeed, McNamara himself was a notable exception in this sense. In his memoirs published in 1996, McNamara publicly admitted regret for forgoing a golden opportunity for a peace settlement with North Vietnam in 1966, when "North Vietnam made "a very specific peace offer" that the United States did not act upon (McNamara 1995: 325). In his memoir, McNamara wrote of the US policy in Vietnam, "We were wrong. We were terribly wrong. We owe it to future generations to explain why" (McNamara 1995: 7). More often than not politicians would avoid admitting to mistakes, at best stating that "mistakes were made." Political analyst William Schneider has suggested these expressions are best referred to as "past exonerative" statements (Brodermarch 2007).

Politicians have a lot to lose by admitting mistakes. Such admissions present them as lacking in judgment and subsequently lending power to their political rivals. For politicians, therefore, the experience of regret is a luxury that should be avoided at all costs, and inaction inertia is all about avoiding regret, and therefore particularly relevant here. Moreover, inaction inertia is about actions that were not taken. It is interesting to note that according to research in psychology, in the long-term, inactions are potent sources of regret even more so than actions (Bonnefon \& Zhang 2008; Gilovich \& Medvec 1994, 1995; Gilovich, Medvec \& Kahneman 1998). Yet inaction is more easily concealed. Indeed, only three decades after the Vietnam War did we hear about the golden peace opportunity missed. Thus, the ability to identify and recognize inaction inertia situations is especially important in politics.

\section{Gender Differences}

A comparison of the performance of male and female participants revealed no gender differences (see Table 4). The relationship between gender and the number of rounds played was not significant $\left(\chi^{2}(2, \mathrm{~N}=216)=2.965\right.$, NS $)$. These results are inconsistent with previous findings by Terris and Tykocinski (2016) which suggested that males are more susceptible to inaction inertia than females.

The absence of gender differences in the present experiment could possibly be attributed to the way the study was run. Previous experiments were conducted in the laboratory, thus "exposing" participants' gender identity, whereas 
TABLE 4 Average negotiation rounds, by condition and gender

\begin{tabular}{lllllll}
\hline & $\begin{array}{l}\text { Male } \\
\text { N=139 }\end{array}$ & & \multicolumn{5}{l}{ Female } \\
& & & & \\
& & & & \\
& N $=77$ & & \\
& & M & SD & N & M & SD \\
\hline Large Difference & 46 & 6.11 & 2.93 & 27 & 5.22 & 2.65 \\
$\begin{array}{l}\text { Small Difference } \\
\text { Control }\end{array}$ & 48 & 5.23 & 2.49 & 24 & 4.08 & 2.06 \\
& 45 & 4.93 & $\mathbf{2 . 1 7}$ & $\mathbf{2 6}$ & $\mathbf{3 . 9 6}$ & $\mathbf{2 . 0 3}$ \\
\hline
\end{tabular}

the current study was conducted online, and gender information was only collected in the post-negotiations questionnaire. It is possible that the absence of gender effects is actually attributable to the relative anonymity of participants in the online task.

In addition, although the pattern of gender differences was previously observed in both conflict scenarios, they were particularly notable and significant in the context of the hostage negotiation rather than the territorial dispute scenario. It is possible that the different sensitivity of females is likely to emerge particularly when lives are immediately at stake.

Further research employing different methods of creating gender identity salience and involving different negotiation contexts is needed to help clarify the role of gender differences in inaction inertia.

\section{Conclusions}

In this article, we presented a methodology and analysis that facilitated the successful transfer of the inaction inertia effect into the complex world of dynamic international negotiations. ${ }^{7}$ The results of this study enrich our understanding of negotiation deadlocks. As the literature shows, negotiations deadlocks can be the result of a multitude of causes. However, whereas it is relatively difficult to implement dramatic governmental changes or evoke an economic change, the inaction inertia mindset is more amenable to successful interventions. In this sense, awareness of the existence and impact of inaction inertia is important. As with other psychological effects and motivations,

7 Importantly, with some adjustments the negotiation platform developed can be applied to explore other issues relevant to negotiation contexts. 
decision-makers themselves may not be fully cognizant of inaction inertia and its ability to drive players into a state of non-cooperation. Thus, awareness may serve as a first step toward putting negotiations back on track. In the field of psychology, interventions such as decoupling (disassociating the past from the present) (Van Putten, Zeelenberg \& Van Dijk 2007) and "future focus" (Tykocinski, Pittman \& Tuttle 1995) were found to effectively facilitate breaking away from the shadows of passed missed opportunities. These methods could easily be applied in the environment of international negotiations and contribute to conflict resolution efforts. Mediators could play a significant role by helping the parties identify inaction inertia patterns and assisting in breaking away from these psychological situations.

Although the findings reported in this article bring us closer to the goal of studying inaction inertia in dynamic multi-issue international negotiations, we note some limitations. First, our participants were not trained politicians or negotiators. A common critique of experimental research in political science that has generated much debate among scholars relates to the external validity of experiments using "laypeople," in particular, students, as participants (McDermott 2002; McDermott et al. 2011; Mintz et al. 2006; Stoll 2004). While there is no agreement as to the degree to which one might generalize from such experiments to real world political elites, there is general consensus that, at its core, experimental research offers important insights into how human beings obtain and process information. Moreover, these insights, which shed light on biases in decision-making are useful in building more powerful theories that help us understand international politics (Kaufman 1994: 558). Furthermore, experimental research allows for control of the independent variables in a way that cannot be obtained in the analysis of real cases. Therefore, we argue that a mixed method approach combining experimental and case analysis is probably the most promising approach here as it provides evidence of inaction inertia behavior patterns in real negotiations, while revealing, through experimentation, the specifics of how it operates.

A related concern regarding the findings presented here may be that in our experiments we have a single decision maker, whereas in real life, international negotiations are often conducted by teams. One could argue that it is possible that negotiation decisions reached by a group create some diffusion of the responsibility on part of the negotiators themselves, which would reduce the potential of regret and moderate inaction inertia. However, although negotiations are often a team effort, negotiation decisions, particularly in the realm of war and peace, are usually linked back to the leaders of the parties involved. For this reason, Moshe Dayan allowed himself to blame Israeli Prime Minister Golda Meir for missing an opportunity to reach a settlement with Egypt in 1971 
that could have prevented the war, even though he himself was part of the decision-making team. Finally, the online negotiation method has certain constraints. While the computerized interface allowed us to maintain control and create comparable conditions, in choosing this setting we lost some of the hot realistic emotion-laden encounters that are characteristic of face-to-face interactions. That said, participants' feedback suggested that the inclusion of the introductory video as well as the news bulletins were successful in immersing them in the situation and contributed to the realistic "feel" of the negotiations. Moreover, unlike actual politicians, our negotiators were never in fear of public criticism or loss of power. Real politicians would have more to lose. Indeed, this is what would make them even more susceptible to inaction inertia. The fact that we were able to demonstrate inaction inertia in these controlled conditions only speaks to the strength of the inaction inertia effect.

\section{References}

Bazerman, M.H., T. Magliozzi and M.A. Neale (1985). "Integrative Bargaining in a Competitive Market." Organizational Behavior and Human Decision Processes 35, 3: 294-313.

Bazerman, M.H., J.R. Curhan, D.A. Moore and K.L. Valley (2000). “Negotiation.” Annual Review of Psychology 51, 1: 279-314.

Bonnefon, J. F. and J. Zhang (2008). "The Intensity of Recent and Distant Life Regrets: An Integrated Model and a Large-Scale Survey." Applied Cognitive Psychology 22, 5: 653-662.

Brodermarch, J.M. (2007). "Familiar Fallback for Officials: Mistakes Were Made." The New York Times, March 14.

Butler, A. and S. Highhouse (2000). "Deciding to Sell: The Effect of Prior Inaction and Offer Source." Journal of Economic Psychology 21, 3: 223-232.

De Dreu, C. K. and C. McCusker (1997). "Gain-Loss Frames and Cooperation in Two-Person Social Dilemmas: A Transformational Analysis." Journal of Personality \& Social Psychology, 72, 5: 1093-1106.

Dehghani, M., P. Carnevale and J. Gratch (2014). "Interpersonal Effects of Expressed Anger and Sorrow in Morally Charged Negotiation." Judgment and Decision Making 9, 2: 104-13.

Eban, A. (1992). Personal Witness: Israel through My Eyes. New York: Putnam.

Epley, N. and T. Gilovich (2006). "The Anchoring-and-Adjustment Heuristic: Why the Adjustments Are Insufficient." Psychological Science 17, 4: 311-318. 
Fearon, J. (1995). "Rationalist Explanations for War." International Organization 49, 3: $379-414$

Galinsky, A.D. and T. Mussweiler (2001). "First Offers as Anchors: The Role of Perspective-Taking and Negotiator Focus." Journal of Personality and Social Psychology 81, 4: 657-669.

Gilovich, T. and V.H. Medvec (1994). "The Temporal Pattern to the Experience of Regret." Journal of Personality and Social Psychology 67, 3: 357.

Gilovich, T. and V.H. Medvec (1995). "The Experience of Regret: What, When, and Why." Psychological Review 102, 2: 379 .

Gilovich, T., V.H. Medvec and D. Kahneman (1998). "Varieties of Regret: A Debate and Partial Resolution." Psychological Review 105, 3: 602.

Golan, G. (2015). Israeli Peacemaking Since 1967: Factors behind the Breakthroughs and Failures. Abingdon: Routledge.

Kahneman, D. (1992). "Reference Points, Anchors, Norms, and Mixed Feelings." Organizational Behavior \& Human Decision Processes 51, 2: 296-312.

Kahneman, D. and A. Tversky (200o). "Conflict Resolution: A Cognitive Perspective," in D. Kahneman and A. Tversky, editors, Choices, Values and Frames. Cambridge: Cambridge University Press, Russell Sage Foundation.

Kaufmann, C. (1994). "Out of the Lab and into the Archives: A Method for Testing Psychological Explanations of Political Decision Making." International Studies Quarterly 38: 557-586.

Kissinger, Henry (1979). The White House Years. Boston: Little, Brown and Co.

Kydd, A. (2005). Trust and Mistrust in International Relations. Princeton: Princeton University Press.

Larson, D.W. (1997). "Trust and Missed Opportunities in International Relations." Political Psychology 18, 3: 701-734.

Liu, H.H. and H.Y. Chou (2018). "Promotional Formats and Inaction Inertia." Journal of Economic Psychology 66: 22-32

Liu, H.H. and H.Y. Chou (2019). "The Effects of Promotional Package Frames and Price Strategies on Inaction Inertia." Psychology and Marketing 36: 214-228.

Loewenstein, G. and J.S. Lerner (2003). "The Role of Affect in Decision Making," in R.J. Davidson, K.R. Scherer, and H. H. Goldsmith, editors, Series in Affective Science. Handbook of Affective Sciences. New York: Oxford University Press, 619-642.

Maoz, Zeev (2006). Defending the Holy Land. Ann Arbor: University of Michigan Press. McDermott, R. (2002). "The Experimental Method in Political Science." Annual Review of Political Science V: 31-61, https://doi.org/10.1146/annurev.polisci.5.o91001.170657. McDermott, R. (2009). Political Psychology in International Relations. Ann Arbor: The University of Michigan Press. 
McDermott, R., N. Wernimont and C. Koopman (2011). "Applying Psychology to International Studies: Challenges and Opportunities in Examining Traumatic Stress." International Studies Perspective 12: 119-135.

McNamara, R. (with B. VanDeMark) (1996). In Retrospect: The Tragedy and Lessons of Vietnam. New York: Random House, Inc.

Mintz, A., S. Redd and A. Vedlitz (2006). "Can We Generalize from Student Experiments to the Real World in Political Science, Military Affairs, and International Relations?" Journal of Conflict Resolution 50, 5: 757-776.

Pittman, T.S., O.E. Tykocinski, R. Sandman-Keinan, and P. Matthews (2008). "When Bonuses Backfire: An Inaction Inertia Analysis of Procrastination Induced by a Missed Opportunity." Journal of Behavioral Decision Making 21: 139-150.

Power, Samantha (2003). "War and Never Having to Say You're Sorry." The New York Times, December 14.

Quandt, William B. (2005). Peace Process: American Diplomacy and the Arab-Israeli Conflict since 1967. Washington, DC: Brookings Institution Press.

Renshon, J. and J. Lerner (2012). "The Role of Emotions in Foreign Policy Decision Making," in J. Daniel Christie and Christina Montiel, editors, Encyclopedia of Peace Psychology. Malden, MA: Wiley Blackwell Press, 13-17.

Renshon, J., J. Lee and D. Tingley (2017). "Emotions and the Micro-Foundations of Commitment Problems." International Organization 71, S1: S189-S218.

Ross, L. and C. Stillinger (1991). "Barriers to Conflict Resolution." Negotiation Journal 7: 389-404

Sevdalis, N., N. Harvey and M. Yip (2006). "Regret Triggers Inaction Inertia - but which Regret and How?” British Journal of Social Psychology 45: 839-853.

Tannen, D. (1994). Gender and Discourse. Oxford: Oxford University Press.

Terris, L.G. (2017). Mediation of International Conflicts: A Rational Model. New York: Routledge.

Terris, L.G. and O.E. Tykocinski (2016). "Inaction Inertia in International Negotiations: The Consequences of Missed Opportunities." British Journal of Political Science 46, 3: 701-717.

Tessler, M., J. Nachtwey and A. Grant (1999). "Further Tests of the Women and Peace Hypothesis: Evidence from Cross-National Survey Research in the Middle East." International Studies Quarterly 43, 3, 519-531.

Tsiros, M. and D.M. Hardesty (2010). "Ending a Price Promotion: Retracting it in One Step or Phasing it Out Gradually." Journal of Marketing 74: 49-64.

Tykocinski, O.E., T.S. Pittman and E.E. Tuttle (1995). "Inaction Inertia: Foregoing Future Benefits as a Result of an Initial Failure to Act." Journal of Personality and Social Psychology 68: 793-803. 
Van Evera, Stephen (2001). Causes of War: Power and the Roots of Conflict. Ithaca: Cornell University Press.

Van Putten, M., M. Zeelenberg, and V.E. Dijk (2007). "Decoupling the Past from the Present Attenuates Inaction Inertia." Journal of Behavioral Decision Making 20, 1: 65-79.

Van Putten, M., M. Zeelenberg, V.E. Dijk, and O.E. Tykocinski (2014). "Inaction Inertia." European Review of Social Psychology 24, 1: 123-159.

Whyte, G. and J.K. Sebenius (1997). "The Effect of Multiple Anchors on Anchoring in Individual and Group Judgment." Organizational Behavior \& Human Decision Processes 69, 1: $75^{-85}$.

Zeelenberg, M. and M. Van Putten (2005). "The Dark Side of Discounts: An Inaction Inertia Perspective on the Post-Promotion Dig." Psychology \& Marketing 22: 611-622. 